\title{
Smoking Profiles in Pre-intervention Ischaemic Heart Disease Patients
}

\author{
Muhammad Asghar Nawaz , A. Javed, P. Curry, A. Murday \\ Glasgow Royal Infirmary NHS Glasgow \\ *Corresponding Author: m.nawaz@nhs.net
}

Copyright $@ 2013$ Horizon Research Publishing All rights reserved.

\begin{abstract}
Smoking cessation intervention is a cost effective method of preserving life and reducing ill health and is believed to be the most effective lifestyle change after a myocardial event. The pre-operative period is particularly useful time to implement smoking cessation advice and to offer help. Smokers undergoing surgery have an increased risk of both intra and post-operative complications. Nearly a six-fold increase in post-operative pulmonary complications in current smokers was demonstrated in a study. There is much debate over the optimum time to stop smoking to reduce post-operative complications. The effects of smoking cessation prior to surgery may be dependent on the length of time cessation occurred before surgery. Our study investigates the smoking profiles of patients awaiting cardiac intervention for ischaemic heart disease and what advice and help these patients are offered. All patients randomly selected had established diagnosis of ischaemic heart disease needing cardiac intervention; either coronary artery graft bypass or angioplasty. This study shows different trends in methods used to successfully give up smoking in the ex-smoking group compared to the methods used in attempting to give up in the smoking group. Smoking cessation advice and the offer of additional services can never be more important in the time prior to cardiac surgery.
\end{abstract}

Keywords Ischemic heart disease, Smoking, Coronary angioplasty, CABG

\section{Introduction}

Smoking cessation intervention is an extremely cost effective method of preserving life and reducing ill health and is believed to be the most effective lifestyle change after a myocardial event.

Patients who stop smoking after an acute myocardial infarction significantly reduce their risk of death compared to those who continue to smoke (1). Smoking cessation following a myocardial event has been associated with a relative reduction in mortality of $35-45 \%$ after 3 to 5 years (2). Similar findings in another study showed a $50 \%$ reduction in mortality in 3 to 5 years (3). This reduction increases with time. After 13 years, $63 \%$ of those who stopped smoking are still alive compared to only $18 \%$ of those who continued to smoke (4). Smoking cessation following a myocardial infarction has also been shown to reduce the risk of further cardiac events (5). Patients undergoing coronary artery bypass graft who continue to smoke are at increased risk of death, MI (6) and thrombosis of the graft (7).

The preoperative period may be a particularly useful time to implement smoking cessation advice and to offer help. Smokers undergoing surgery have an increased risk of both intra and postoperative complications $(8,9)$. Nearly a six fold increase in post-operative pulmonary complications in current smokers was demonstrated in a study that found $22 \%$ of current smokers, $12.8 \%$ of past smokers and $4.9 \%$ of never smokers get post-operative complications (8). This study is backed by other studies that have shown a 3 to 5 fold increase in post-operative pulmonary complications $(6,7)$.

Studies have shown increased wound related complications in those patients who continue smoking prior to surgery $(9,12)$. A study on post-operative complications on hip and knee replacements have demonstrated a significant reduction in wound and cardiovascular complications and the requirement of secondary surgery in those who stop smoking prior to surgery. They found wound complications in $5 \%$ of the smoking cessation intervention group in comparison to $31 \%$ of the control group, cardiovascular complications in $10 \%$ of the intervention group compared to none in the control group and $4 \%$ requiring second surgery in comparison to $15 \%$ in the control group (13).

There is much debate over the optimum time to stop smoking to reduce post-operative complications. The effects of smoking cessation prior to surgery may be dependent on the length of time cessation occurred before surgery. Reducing smoking within 1 month of surgery has been shown not to reduce the risk of post-operative pulmonary complications. This study also showed that patients giving up smoking closest to surgery were at the most risk of developing post-operative pulmonary complications (8). This could possibly be explained by an increased 
accumulation of mucus in the airways of smokers leading to pulmonary infections (14) coupled with immobilisation during surgery and anaesthesia (9).

However, short-term preoperative smoking cessation may confer benefits, as the harmful effects of increased carbon monoxide and nicotine in the blood can be lost within 24-48 hours of smoking cessation (15). Oxygen delivery is reduced to the heart and tissues as increased carbon monoxide levels binds to the haemoglobin instead of oxygen (16). Increased levels of carbon monoxide are associated with reduced coronary flow and increased myocardial irritability $(17,18)$.

A study specifically examining cessation of smoking prior to coronary artery bypass grafting advise that smoking cessation should occur 2 months prior to surgery in order to be beneficial. It found smokers who stopped within two months before surgery had nearly 4 times the rate of pulmonary complications than those who stopped before two months prior to surgery. It also showed that cessation at 6 months prior to surgery had outcomes similar to non-smokers (19).

Studies have shown that there are particular longer term benefits associated with smoking cessation at the time of coronary intervention. A 15 year follow up study of patients undergoing coronary artery bypass surgery has shown patients who continue to smoke have more than double the risk of MI, angina and re-operation at 1 year with the risk increasing at 5 years (20). A study illustrating the effects of smoking status on long-term outcome of percutaneous revascularization have shown persistent smokers to have a greater relative risk of death and Q-wave infarction (21).

Cardiac surgery is believed to be a time where the patient is most likely to want to stop smoking and is therefore possibly the time where the patient will be most receptive to advice. It is an ideal situation to initiate smoking cessation intervention. This study investigates the smoking profiles of patients awaiting cardiac intervention for ischaemic heart disease and what advice and help these patients are offered.

\section{Aims}

Our study aimed to question 50 patients randomly selected with an established diagnosis of ischaemic heart disease who were admitted to cardiac department in Glasgow Royal Infirmary for cardiac intervention; either coronary artery graft bypass or angioplasty. This study is based on a semi-quantitative questionnaire using the transtheoretical model of change (42) and the fagerstrom nicotine dependency scores (19).

Aims were as follows:

- To determine

(1) percentage of smokers, ex smokers and non smokers

(2) an association between deprivation and smoking status

(3) patients awareness of the increased risks of post-operative complications associated with smoking
(4) the nicotine dependency score of all smokers and ex-smokers at time of smoking and compare the results

(5) the willingness of patients to stop smoking by using a transtheoretical model of change

(6) the advice and services that have been offered to smokers and ex-smokers when attempting to cease smoking

(7) duration of successful smoking cessation in ex-smokers

- To determine a relationship of success of smoking cessation with:

(1) interventions used

(2) number of attempts to date

(3) number of cigarettes smoked per day

(4) type of diagnosis of ischaemic heart disease

(5) past interventions undertaken

\section{Inclusion / Exclusion Criteria}

Patients with an established diagnosis of ischaemic heart disease in their medical notes in cardiology department of Glasgow Royal Infirmary. The patients were interviewed directly by the investigators. Smokers were classified as those who continue smoking and those who have given up smoking in the last month.

If patients smoked cigars or pipes in addition to cigarettes, it was noted but not taken into account in the study. It was however, only one patient who had smoked cigars, pipe and cigarettes.

\section{Data Collected}

See appendix 1 for smoking cessation questionnaire

For each patient demographic details including gender, date of birth, postcode, ethnic origin, education, employment were collected. The patients were asked if they smoked or had previously smoked, how old they were when they started and also what age they had stopped in the case of ex-smokers. Number of years smoked and in the case of ex-smokers also the number of years stopped was calculated. They were asked how many cigarettes were smoked per day and from this the number of packets smoked per year was calculated. The patients self verified their own smoking status. The patients were asked a series of questions to determine their classification within the transtheoretical model of change. If they believed smoking has no adverse effects on their health they were classified within the precontemplative stage. If they believed smoking has an adverse effect on their health they were classified within the contemplative stage. If they expressed a wish to stop smoking but had not acted upon this they were classified within the preparation stage. If they had acted upon the wish to stop smoking they were classified within the active stage. If they had been able to successfully stop smoking for more than one month they were classified 
within the maintenance stage. If they had given up and relapsed they were classified within the relapse stage. A series of questions were also asked to determine their fagerstorm nicotine dependency scores including how soon after they woke up they had their first cigarette, if they found it difficult to refrain from smoking in places where it is forbidden, which cigarette in the day would be most difficult to give up, how many cigarettes per day they smoke, if they smoke more frequently during the first hours after awakening than during the rest of the day and if they smoke when in bed unwell. The insight of the patients was gauged by asking if they were aware that cigarette smoking is associated with increased post-operative complications. The patients were asked who within their social circle smoked. The diagnosis of ischaemic heart disease and any past cardiac intervention was noted from the patient's medical notes.

\section{Results}

Of the 50 patients $16 \%$ (8) were smokers, $66 \%$ (33) were ex-smokers and $18 \%$ (9) were non-smokers; the rest of the results are shown in the graphs below:

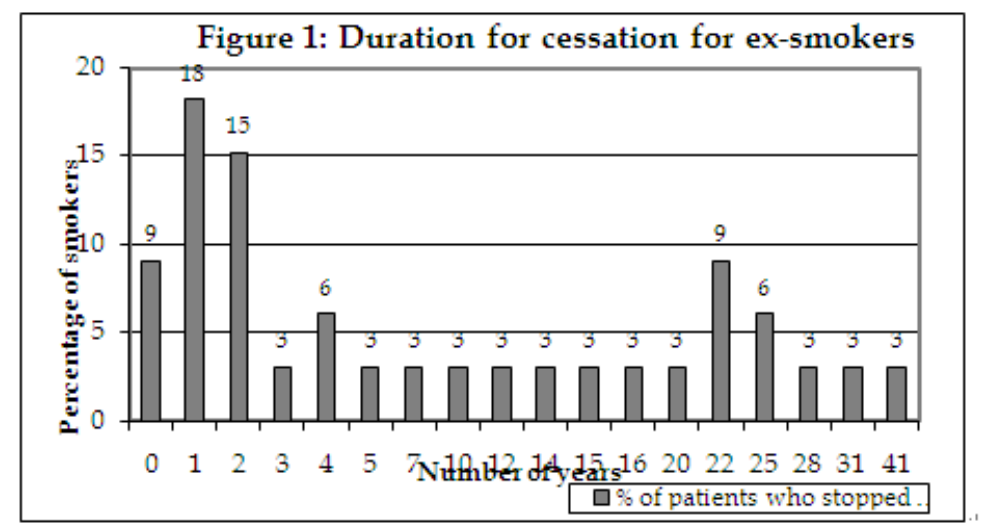

Figure 1. shows that $9 \%$ of the patients within the ex-smoking group have given up within the last year with $91 \%$ having stopped smoking for 1 year and beyond.

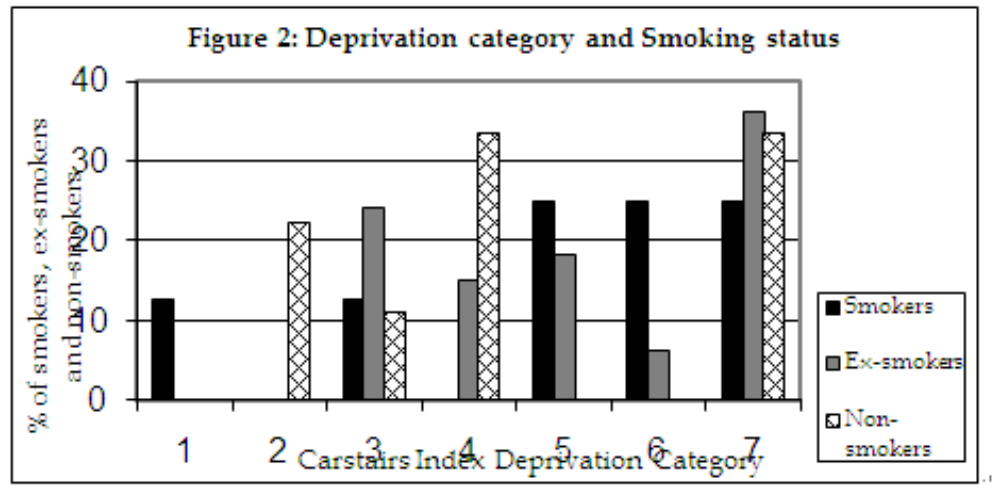

Figure 2. shows that there is no significant trend between smokers and non-smokers with socio-economic status

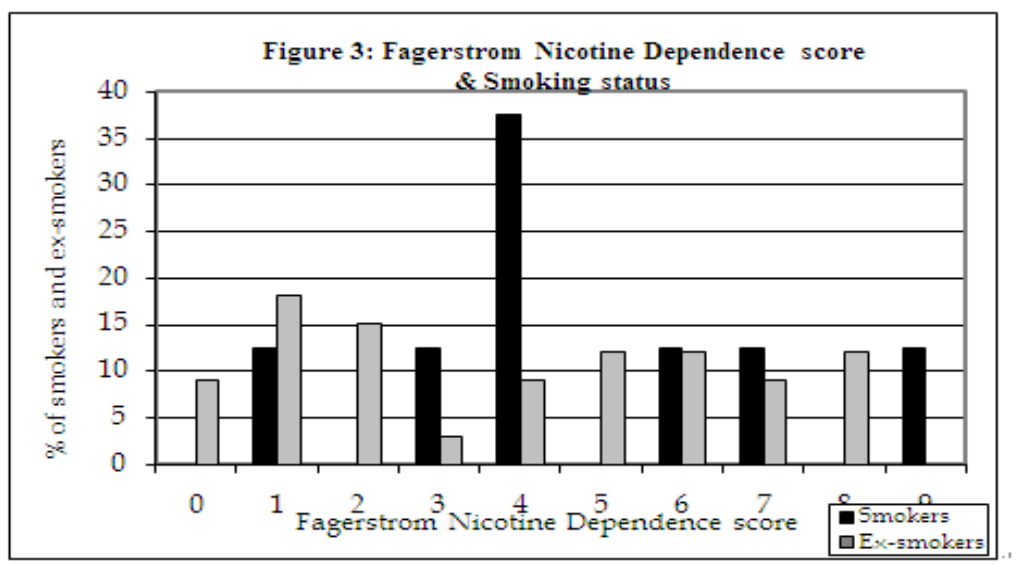

Figure 3. shows that on average smokers have a higher nicotine dependence score than non-smokers 
Figure 4: Percentage of smokers in each stage of theTranstheoretical model of change

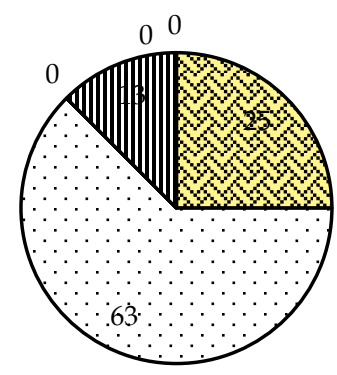

\begin{tabular}{|l}
\hline $\begin{array}{l}\text { 口Pre- } \\
\text { contemplative } \\
\text { 口Contemplative }\end{array}$ \\
घPreparation \\
$\square$ Action
\end{tabular}

Figure 4. shows that non of the smokers are classified with in the pre-contemplative or contemplative and are all classifies within the preparation (25\%) or action stage $(63 \%)$ with $13 \%$ in relapse

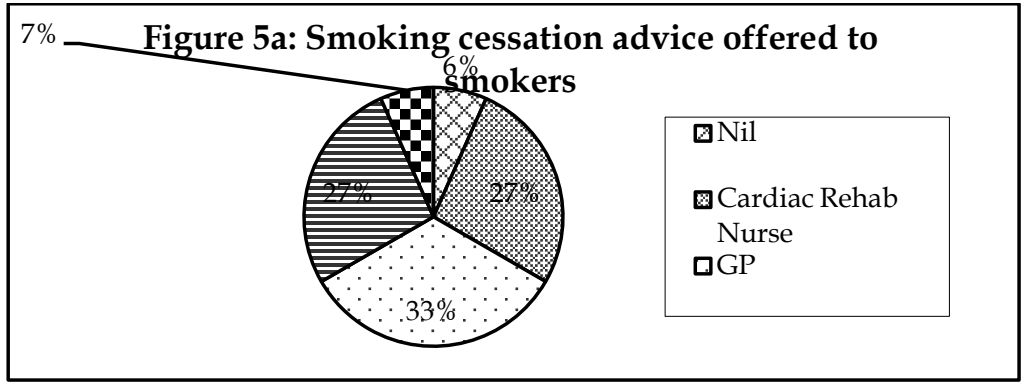

$2 \%$ Figure 5b: Smoking cessation advice offered to ex-

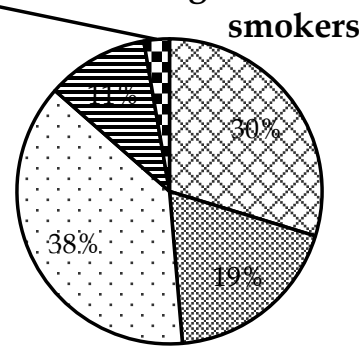

Nil
Cardiac Rehab
Nurse
a

Figure 5a 5b. show the different sources of smoking cessation advice recalled by smokers and ex-smokers respectively

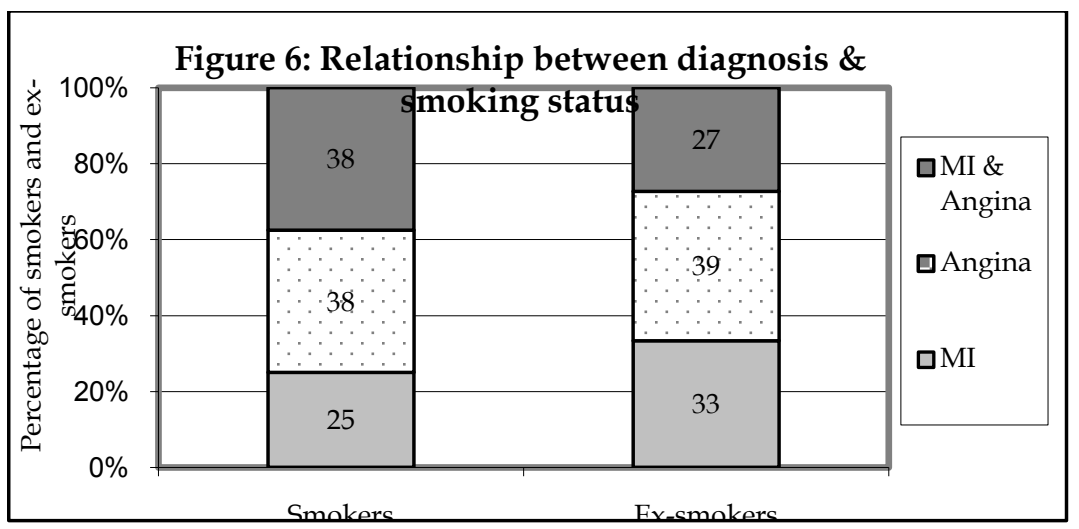

Figure 6. shows $33 \%$ of ex-smokers have been diagnosed with MI only compared to $25 \%$ of smokers 


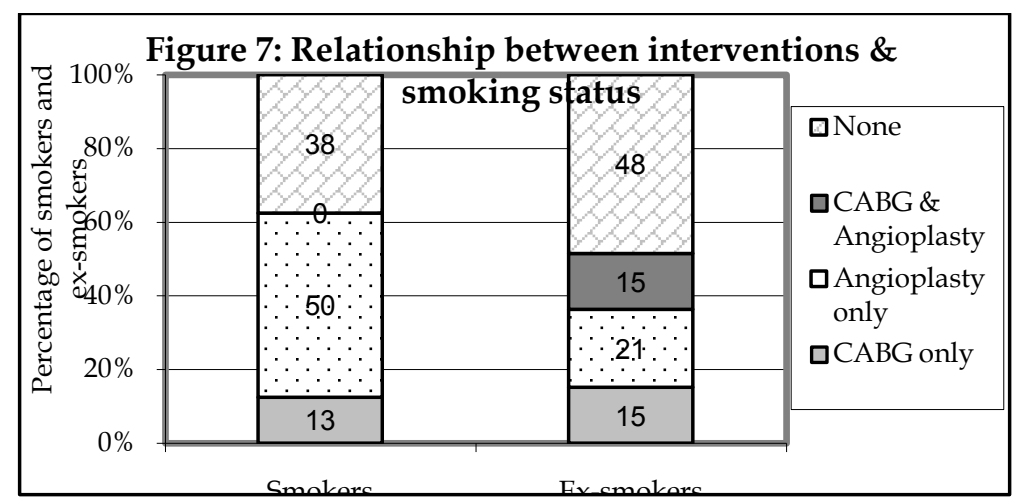

Figure 7. shows that $30 \%$ of ex-smokers have undergone CABG in comparison to $13 \%$ of smokers

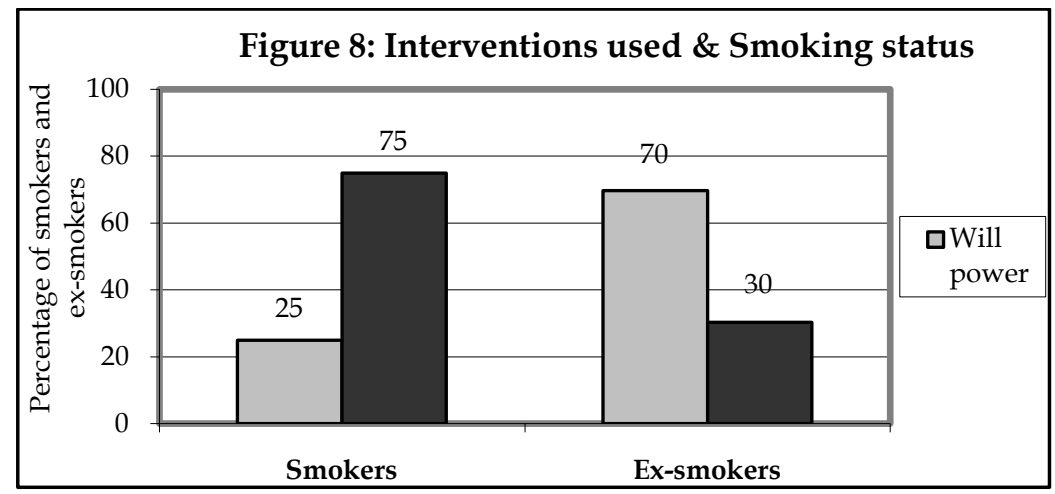

Figure 8. shows $75 \%$ of smokers have used NRT treatment compared to $30 \%$ in the ex-smoking group where $70 \%$ have used will power to successfully stop smoking

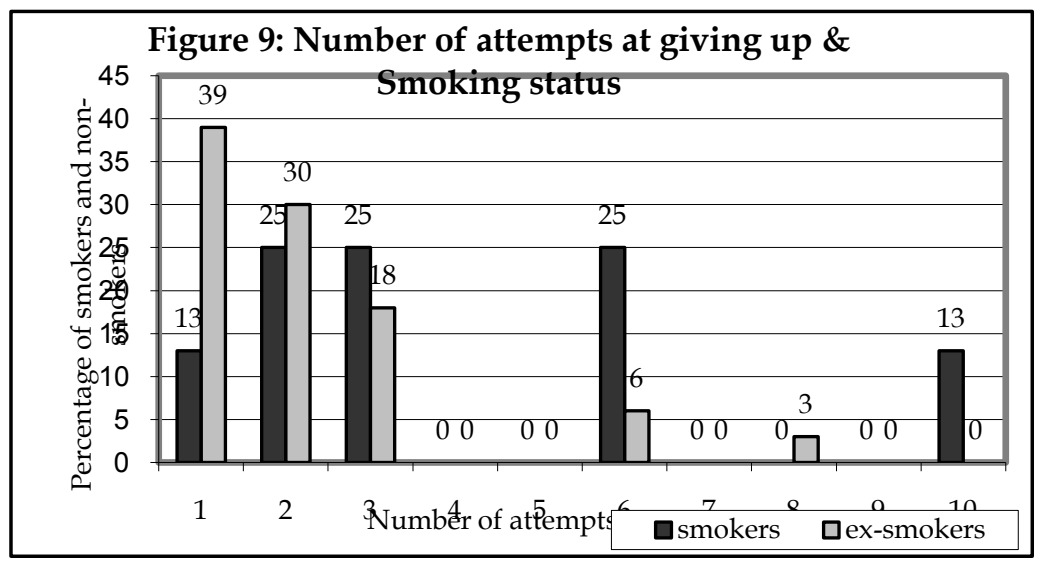

Figure 9. show that the average number of attempts at giving up is 4 to date for smokers and 2 for ex-smokers for successful cessation

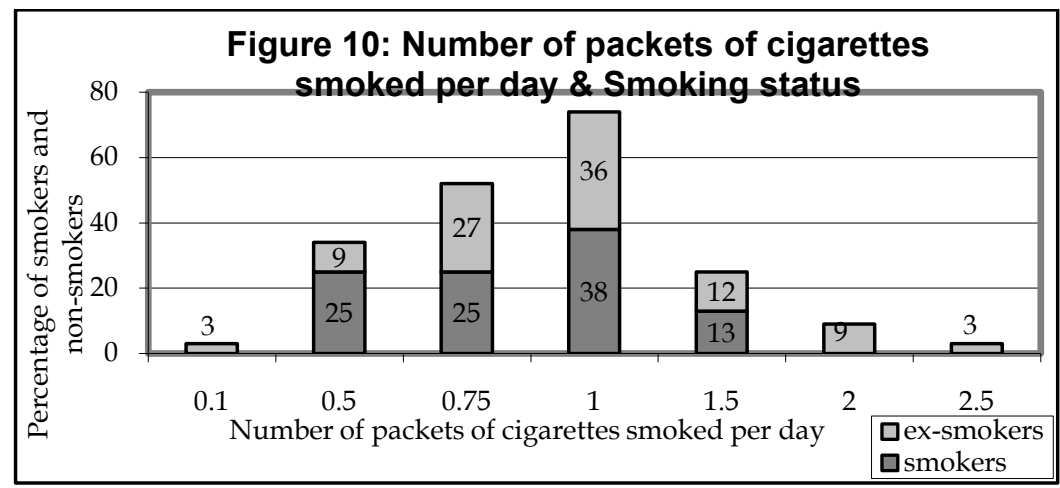

Figure 10. shows no significant difference in the number of cigarettes smoked in each group with the average for both groups being 1 


\section{Results / Discussion}

The carstairs index was used as a measure of social deprivation of the area in which the person lives. This index uses postcode characteristics from the census data. It is considered to reflect material characteristics such as male unemployment and overcrowding (22). The index is categorised as $1-7$ with 7 being the most deprived areas. The distribution of the carstairs index within each of the groups is shown in appendix 1.

Only one address could not be assigned a Carstairs Deprivation Score due to an incomplete postcode. This study showed no significant difference between smokers, ex-smokers, non-smokers and social deprivation.

Physical nicotine addiction is assessed in each patient by the Fagerstrom nicotine dependency index as seen in the questionnaire. This involves asking the patient several questions including how soon after they wake up do they have their first cigarette, how many cigarettes per day do they smoke, do they find it difficult not smoking when others around them are smoking, which cigarette in the day is hardest to give up, do they smoke more cigarette in the morning when they first wake up than the rest of the day and would they smoke even if they were so ill that they were in bed most of the day. Each possible answer is correlated to a score interpreted by $0-2$ as very low dependence, 3-4 low dependence, 5 medium dependence, 6-7 high dependence and 8-10 very high dependence (19).

This study found no correlation between the number of cigarettes smoked per day by the smoking group, in comparison to the number of cigarettes smoked previously per day by ex-smokers. This is contrary to other studies which found that the higher average number of cigarettes smoked per day was related to continued smoking and those who successfully quit, smoked on average less cigarettes per day $(24,25)$. However, we found that smokers on average have a higher nicotine dependency score in comparison to the ex-smokers who have successfully quit. $10 \%$ more ex-smokers than smokers have a nicotine dependency score of 4 or less. A high level of nicotine addiction was also found to be a negative predictive factor in the success of smoking cessation in similar studies of smoking cessation in acute coronary heart disease patients $(24,26)$. It was found to be a negative predictive factor in both the intervention and usual care group (26). The Fagerstrom nicotine dependency score does take into account the number of cigarettes smoked per day but also of other nicotine dependency factors (19).

All patients interviewed were asked about their willingness to give up and depending on the answer are classified into precontemplative, contemplative, preparation, action, maintenance and relapse stages. The individuals in each stage of the transtheoretical model have different attitudes to their behaviour, hence cannot be treated as a homogenous group when trying to alter their behaviour. Each stage of the transtheoretical model of change is related to a certain approach tailored to the patients' stage (27). Guidelines outline the aims to be met by the health services and an idea of suitable approaches for each specific group. In the precontemplative stage the main aim is to make the patient aware of the risks and problems associated with their current behaviour. Brief interventions by doctors have been shown to increase cessation rates by $5 \%$ in comparison to control groups (28). Hence, routinely asking patients about their smoking habits is beneficial and aids smoking cessation. The aim of the next stage, the contemplative stage further tips the balance by not just highlighting risks and problems of behaviour which they are already aware of but to evoke reasons to change and highlight the risks of not changing. Studies have shown patients with coronary artery disease and patients who have underwent coronary artery bypass and who have intention to quit are more likely to succeed $(29,30)$. In our study, none of the patients in the smoking group fell into either the precontemplative or contemplative stages. This might be a reflection of the success of health campaigns and the fact that they have already experienced either angina or myocardial infarction and are therefore already aware of the adverse effects of their unhealthy behaviour and have already made the decision to try to stop.

Patients in the preparation stage need help to determine the best course of action to take. The emphasis is to try to get the patients to act on their decision now that they are prepared to make the change. $25 \%$ of the smokers interviewed identified themselves as being in this stage. It can therefore be supposed that this group might be receptive to any advice offered to assist their attempts at stopping smoking from both doctors and the smoking cessation services.

Patients in the action stage have already tried interventions such as nicotine replacement therapy, Zyban tablets or group therapy. These patients need help to take steps towards the desired change. Doctors and smoking cessation services can assist such patients by offering the various interventions available and advising each patient on interventions that are best suited for them. $62.5 \%$ of smokers in this study, having tried various interventions fall into this stage. Since the majority of smokers have tried acting upon their decision, the health profession should focus on this group, giving them positive affirmation on each encounter supporting their decision and supporting them throughout their attempts to give up smoking.

For those in the maintenance stage, the aim is to help the patient identify and use strategies to prevent relapse. In our study, $9 \%$ of the patients within the ex-smoking group have given up within the last year with $91 \%$ having stopped smoking for 1 year and beyond. For those who have relapsed, the aim is to help them renew the processes of contemplation, preparation and action without becoming stuck or demoralised because of relapses. $12.5 \%$ of smokers in this study belonged to the relapse stage. They were keen on attempting yet again to change their habits and showed 
interest in any support available to them by the health services to assist them through the different stages of smoking cessation.

As all the patients in our study are classified in the cycle of change within contemplative, action or relapse stages, they have an increased chance of long term success than if they were at the precontemplative stage.

In this study there were considerable differences between the smoking group and ex-smoking group in recalling what smoking cessation advise had been offered and by whom. The main differences include $7 \%$ of smokers recalling no advice offered by any health profession compared to $30 \%$ of ex-smokers. However, this may be simply due to the fact that ex-smokers will not have been offered advice recently and therefore do not remember. 7\% of smokers recall advice from their cardiac surgeon compared to $3 \%$ of ex-smokers. This may be explained by the ex-smokers having already quit by the time they require surgery. In the smoking group most advice about smoking cessation was recalled from the GP $(32 \%)$, closely followed by the cardiac rehabilitation nurse $(27 \%)$ and the cardiologist $(27 \%)$.

This study has found a correlation between severity of both diagnosis and intervention with smoking status. A diagnosis of myocardial infarction is more common amongst ex-smokers with $33 \%$ diagnosed with MI compared to only $25 \%$ of smokers. Coronary artery bypass surgery $(\mathrm{CABG})$ is also more common within the ex-smoking group. A possible explanation for this is that patients with MI or patients who have undergone $\mathrm{CABG}$ are more likely to give up smoking as they may have an increased determination as their health has been more adversely affected.

A randomised control study of smoking intervention found similar findings. In the normal care group, a diagnosis other than myocardial infarction was a negative predictive indicator of smoking cessation. These patients, however, were more susceptible to intervention as they were more likely to quit in the intervention group (20). In contrast, another study has shown that $30-40 \%$ of patients stop smoking after a coronary event but a diagnosis of MI did not lead to more smoking cessation than any other coronary diagnosis (31).

This study found previous CABG to be slightly more common in the ex-smoking group than the smoking group $(15 \%$ vs $13 \%)$. A follow up of smoking cessation in patients with coronary heart disease at 5 months and 6 years found that patients who undergo coronary artery bypass have less risk of relapse in smoking cessation (32). A randomised control study found nearly half post CABG patients had stopped smoking at 5 years irrespective of whether the patient was in the intervention group with additional smoking cessation advice or the control group (36). This study found previous MI to be a stronger predictive factor in smoking cessation than previous CABG. This was also the finding of a study comparing brief intervention with usual care. It found that MI patients were much more likely to stop smoking at 12 months than patients undergoing bypass surgery (17\%) (24).

This study shows very different trends in methods used to successfully give up smoking in the ex-smoking group compared to the methods used in attempting to give up in the smoking group. The findings are nearly opposing; $70 \%$ of ex-smokers used will power compared to $25 \%$ in the smoking group and only $30 \%$ of ex-smokers used nicotine replacement therapy compared to $75 \%$ in the smoking group. This could possibly be explained by nicotine replacement therapy (NRT) now being more readily available than would have been to those trying to quit in the past. Studies have shown the benefits of NRT. It has been shown to increase the success of quitting by 1.5-2 fold regardless of setting and although beneficial, independent of additional support (33). A study randomly allocating non-cardiac pre-operation patients to intervention group with NRT or to usual care found that patients using NRT were more likely to give up at time of operation with $73 \%$ giving up in comparison to just $56 \%$ of the patients not offered NRT. These statistics however were reduced to $18 \%$ and $5 \%$ respectively three months later (34). The effect of NRT on oxygen consumption is unclear and therefore the use in cardiac patients has been scrutinised. However, a meta analysis based on 35 patients with over 9000 participants found NRT is not associated with an increased risk of cardiovascular events in smokers with a history of cardiovascular disease. There were no excess adverse cardiovascular events in patients assigned to NRT therapy (35). Another concern was patients who continue to smoke while on NRT. However, there has been no synergestic effect of cigarettes and nicotine replacement therapy on cardiac oxygen consumption shown (36).

In this study the patients who had been successful at giving up, the ex-smokers had only required on average 2 attempts compared to the smokers who on average had 4 unsuccessful attempts at giving up. This was also the finding of a randomised control study following smoking cessation up to 5.5 years after coronary artery bypass. It concluded the more attempts a smoker has to quit the less likely they are to succeed.

Several studies have examined the efficacy of interventions to help cardiac patients to give up smoking. Success of intervention is dependent on whether intervention is brief or more intense and delivered over a longer period. Most of the more intense interventions have reported moderate to good results. A randomised trial with intervention of 6 months with 6 months follow up by telephone after MI using specially trained nurses with a focus on preventing relapse have shown smoking cessation rates after 1 year of $71 \%$ in the intervention group and $45 \%$ in usual care group (37). This trial has been backed by another randomised control trial that has shown that smoking cessation programmes significantly reduce the number of smokers 1 year after admission for coronary heart disease. 
The intervention was delivered by nurses without specialist training with an emphasis on fear arousal with 5 month follow up. $57 \%$ stopped smoking in the intervention group whereas only $37 \%$ stopped smoking in the control group (38).

Other studies providing non-intensive intervention easily delivered on a large scale by cardiac rehabilitation nurses, however, have failed to show any significant effects on smoking cessation rates. Brief intervention including written information about smoking, positive health effects of smoking and advice on how to avoid a relapse to MI and bypass surgery patients found no differences between the intervention and control group at 12 months (24). Short term intervention of a 3 session nurse delivered behaviour modification programme with follow up after 5 years following coronary artery bypass graft surgery showed no change between control and intervention.(39)

A study which compared conservative and aggressive smoking cessation treatment after coronary artery bypass surgery found that $59 \%$ were not smoking in the conservative group compared with $85 \%$ not smoking in the aggressive treatment group at 12 months after surgery. The conservative group were followed up monthly and if resumed smoking were asked to enrol in an 8 week smoking cessation program. The aggressive treatment involved an 8 week program initiated immediately after surgery (40).

\section{Limitations}

Problems of this study include the study objects being small in number with a small smoking group. It is dependent upon the patient's self-verification of smoking cessation. Biochemical verification could have been used including nicotine metabolite concentration in urine, expired carbon monoxide reading or salivary cotinine concentration to access whether the patient is still smoking. A study comparing different verifications of smoking cessation has shown chemical verification generally report low falsification rates and suggested rates of deception range from $5-22 \%(35)$. This is therefore a minor limitation. This study makes comparisons of smoking cessation of ex-smokers within this study to the patients who have successfully given up in other studies. However, the patients in our study are already ex-smokers and did not necessarily give up smoking recently.

\section{Suggestions}

Current guidelines for hospitals include:

- Hospitals should keep up to date records of patients smoking status (The four A's are viewed as an acceptable approach-ask, advise, assist, arrange)

- Patients should be informed as early as possible that hospitals are smoke free buildings.

- Patients should receive advice from clinicians to stop smoking, should be offered NRT or bupropion on NHS prescription and be offered referrals to specialist clinics/services.

- Pregnant smokers should be offered specialist support.

- Clinicians and staff involved with discussions of smoking cessation should have required training.

- Patients should have access to a specialist smokers' clinic with specially trained individuals

- Clinics should offer both individual and group treatment

- Clinics should advise on the use of NRT and bupropion (31)

\section{Conclusions}

This study has shown that independently predictive factors of continued smoking among patients with acute coronary syndromes were related to past cardiac history, past cardiac interventions, and to the level of nicotine dependency. These factors should be considered when nurses and doctors are interviewing patients about smoking habits. From this study it can be concluded that all the patients are aware of the risks and want to stop smoking. Patients should be targeted depending on their stage within the transtheoretical model of change and the specific approach tailored for that stage used. Pre surgery clinics are ideal times to interview patients about their smoking habits. The information gained can be used to identify high-risk individuals that can be offered additional anti-smoking and relapse prevention help. The patient is seen by numerous healthcare workers at this time, each time is a window of opportunity. Smoking cessation advice and the offer of additional services can never be more important in the time prior to cardiac surgery. 


\section{Appendix 1 : Smoking Cessation Questionnaire}

Demographic details:

Gender: $\square \mathrm{M} \square \mathrm{F}$ Age: Postcode: Ethnic Origin:

Education: $\square$ Primary $\square$ Secondary $\square$ Tertiary Employment status:

Smoking status: $\square$ Non-smoker $\square$ Smoker $\square$ Occasional smoker $\square$ Ex-smoker

Assessment of patient's willingness to give up smoking:

- Precontemplation stage: Are you aware of the adverse effects of smoking on your health? = Believe

smoking is not bad

- Contemplation stage: Are you aware of the adverse effects of smoking on your health? = Believe

smoking is bad

- Preparation stage: Do you want to try to stop smoking?

- Action stage: Have you tried anything to help you stop smoking?

- Maintenance stage/ Relapse: If you have tried to stop smoking before, have you been successful or unsuccessful?

Insight: $\square \uparrow$ Risk of operation $\quad \square \uparrow$ Risk of complications $\quad \square \uparrow$ Risk of re-operation

Fagerstrom Nicotine Dependency Assessment:

- How soon after you wake up, smoke your first cigarette?

After 60 minutes (0) 31-60 minutes (1) 6-30 minutes (2) Within 5 minutes (3)

- Is it difficult to refrain smoking in places where it is forbidden? No (0) Yes (1)

- Which cigarette would you hate most to give up? The first in the morning (1) Any other (0)

- No of cigarettes per day you smoke? $\quad<10(0) \quad 11-20(1) \quad 21-30(2) \quad>31(3)$

- Do you smoke more frequently during the first hours after awakening? No (0) Yes (1)

- Do you smoke even if you are so ill that you are in bed most of the day? No (0) Yes (1)

Smoking History:

Type of tobacco use: Cigarettes Other Number of pack years:

Age of smoking initiation: If ex-smoker: Number of years smoked: Reason:

Previous Attempts of Smoking Cessation:

Number of attempts: Interventions used: Nicotine replacement therapy Other

Source of smoking cessation advice: $\square$ Nurse $\square$ GP $\square$ Cardiologist/ Surgeon

Smokers in social network: $\square$ Spouse $\square$ Parents $\square$ Friends $\quad \square$ Colleagues

\section{REFERENCES}

[1] Kunihiro K, Hiroshi S and Yasuhoko S. Impact of smoking status on long-term mortality in patients with acute myocardial infarction. Circ J 2005;69:7-12

[2] Critchley JA, Capewell MD. Mortality risk reduction associated with smoking cessation in patients with coronary heart disease. JAMA2003;290:86-97

[3] Wilson K, Gibson N, William A et al. Effect of smoking cessation on mortality after myocardial infarction: meta-analysis of cohort studies.Arch intern Med2000;160:939-14

[4] Daly LE, Mulcahy R, Graham IM, Hickey N. Long term effect on mortality of stopping smoking after unstable angina and myocardial infarction. BMJ 1983; 287:324-326

[5] Sato I, Nishida M, Okita K et al. Beneficial effects of stopping smoking of future cardiac events in male smokers with previous myocardial infarction. JpnCirc J, 1992; 56:217-222

[6] Hermanson B, Omenn GS, Kronmal RA et al. Beneficial six year outcome of smoking cessation in older men and women with coronary artery disease: results from the CASS registry. N Eng J Med 1988;319:1365-1369
[7] Solymoss B, Nadeau P, Millette D et al. Llate thrombosis of saphenous vein coronary bypass grafts related to risk factors. Circulation 1988;78:140-143

[8] Bluman LG, Mosca L, Newman N et al. Preoperative smoking habits and post operative pulmonary complications. Chest 1998;113:883-9

[9] Moller A and Villebro N. Interventions for preoperative smoking cessation. The Cochrane Database of Systematic Review 2005, Issue 3

[10] Akrawi W, Banumof JL. A pathophysiological basis for informed preoperative smoking cessation counselling. Journal of Cardiothoracic and Vascular Anaesthesia1997;11(5):629-40

[11] Schwilk B, Bothner U and Schraag S et al. Perioperative respiratory events in smokers and non-smokers undergoing general anaesthesia. ActaAnaesthesiologicaScandinavica1997;41:348 -55

[12] Silverstien P. Smoking and wound healing. Am J Med $1992 ; 93: 22 s-24 s$

[13] Moller AM, Villebro N, Pedersen $\mathrm{T}$ et al. Effect of preoperative smoking intervention on postoperative complications: A randomised control trial. Lancet 2002;359:114-7 
[14] Lourenco RV, Klimek MF and Borowski CJ. Deposition and clearance of 2 micro particles in the tracheobroncial tree of normal subjects- smokers and nonsmokers. J Clin Invest 1971;50(7):1411-1420

[15] Anderson ME and Belani KG. Short-term preoperative smoking abstinence. Am Fam Physician 1990;41:1191-94

[16] Sheps DS, Herbst MC, Hindrliter Al et al. Production of arrhythmias by elevated carboxyhaemoglobin in patients with coronary artery disease. Annals of Internal Medicine $1990 ; 11: 343-51$

[17] Deanfield JE, Shea MJ, Wilson RA et al. Direct effects of smoking on the heart: silent ischaemiaeffects disturbances of coronary flow. Am J Cardiol 1986;57: 1005-1009

[18] Mehta MC, Jain AC, Mehta AC et al. Cardiac arrythmias following intravenous nicotine: experimental study in dogs. J CardiovascPharmacolTher 1997;2:291-298

[19] Warner MA, Offord KP, Warner ME et al. Role of preoperative cessation of smoking and other factors in postoperative complications: a blinded prospective study of coronary artery bypass patients. Mayo Clin Pros 1989;64:609-16

[20] Voors AA, van Brussel BL, Plokker HT et al. Smoking and Cardiac Events After Venous Coronary Bypass Surgery. A 15 year follow-up study. Circulation 1996;93:42-47

[21] Hasdai D, Garret KN, Grill DE et al. Effect of smoking status on long term outcome after successful percutaneous coronary revascularization N Eng J Med 1997;336: 755-761

[22] Carstairs V and Morris R. Which deprivation? A comparison of selected deprivation indexes. Journal of Public Health. 1991;13(4):318-326

[23] Heatherton TF, Kozlowski LT, Frecher RC et al. The fagerstrom test for nicotine dependence: a revision of the fagerstrom tolerance questionnaire. $\mathrm{Br} \mathrm{J}$ Addict 1991; $86: 1119-1127$

[24] Hajck P, Taylor TZ, Mills P et al. Brief intervention during hospital admission to help patients to give up smoking after myocardial infarction and bypass surgery: randomised control trial. BMJ 2002;324:87-89

[25] Hasdai D, Garret KN, Grill DE et al. Predictors of smoking cessation after percutaneous coronary revascularization. Mayo Clinic Proceedings 1998;73 (3): 205-209

[26] Quist-Paulsen P, Bake PS and Gallefoss F Predictors of smoking cessation in patients admitted for acute coronary heart disease. Eur J CardiovascPrevRehabil2005;12:472-477

[27] Miller, W.R. and Rollnick, S. (1991). Motivational Interviewing: Preparing People to Change Addictive Behavior (p.18). New York: Guilford Press.
[28] Pieterse ME, Seydel ER, De Vries H, Mudde AN, Kok GJ; Effectiveness of a minimal contact smoking cessation program for Dutch general practitioners: a randomised controlled trial; Preventative Medicine 32:182-190 2001

[29] Rigotti NA, McKool KM, Shiffman S et al. Predictors of smoking cessation after coronary artery bypass graft surgery. Results of a randomised trial with 5 year follow up. Ann Intern Med 1991;120:287-93

[30] Rosal MC, Ockene JK, Ma Y et al. Coronary artery smoking intervention study (CASIS): 5 year follow up. Health Psychology1998;17:476-477

[31] Rigotti NA, Singer DE, Mulley Jr AG, Thibault GE. Smoking cessation following admission to a coronary care unit. J Gen Intern Med 1991;6:305-11

[32] Brummet BH, Babyak MA, Mark DC et al. Predictors of smoking cessation in patients with a diagnosis of coronary artery disease. J CardiopulmRehabil 2002;22 (3):143-7

[33] Silagy C, Lancaster T, Stead L et al. Nicotine replacement therapy for smoking cessation (Archive). The Cochrane Database of Systemic Reviews 2002, Issue 4

[34] Wolfenden I, Wiggers J, Knight J et al. A programme for reducing smoking in pre-operative surgical patients: randomised control trial. Anaethesia 2005;60:172-9

[35] Greenland S, Sallerfield MH and Cares SF. A meta analysis to access the incidence of adverse affects associated with the transdermal nicotine patch. Drug Safety 1998;18:297-308

[36] Keeley EC. Pirwitz MJ, Landau RA et al. Intranasal nicotine spray does not augment the adverse effects of cigarette smoking on myocardial oxygen demand or coronary arterial dimensions. Am J Med 1996 ;101(4):357-63

[37] Taylor CB, Houston-Miller N, Killen JD et al. Smoking cessation after acute myocardial infarction: effects of nurse engaged intervention. Ann Intern Med 1990;113:1188-93

[38] Quist-Paulsen P and Gallefoss F. Randomised controlled trial of smoking cessation intervention after admission for coronary heart disease. BMJ 2003;327:1254

[39] Rigotti NA, McKool KM and Schiffman S. Predictors of smoking cessation after coronary artery bypass graft surgery. Results of a randomised trial with 5 year follow up. Annals of internal Medicine 1994:6:305-11

[40] Hilleman DE, Mohiuddin SM and Packard KA. Comparison of conservative and aggressive smoking cessation treatment strategies following coronary artery bypass graft surgery. Chest2004;125:435-438 